\title{
O SOLIPSISMO NAS DECISÕES JUDICIAIS PRODUZIDAS NO PARADIGMA DA FILOSOFIA DA CONSCIÊNCIA E A EXIGÊNCIA DEMOCRÁTICA DA HERMENÊUTICA
}

\author{
Mariana Schalanski ${ }^{1}$ \\ Santiago Artur Berger Sito ${ }^{2}$
}

\section{RESUMO:}

O presente trabalho pretende iluminar a temática das decisões judiciais, no Brasil. Adota, como "método", a fenomenologia hermenêutica, para compreender a forma de decidir processos judiciais, implicando na adoção de determinados entendimentos. Após compreender a lógica temporal que desembocou o ordenamento jurídico nas condições atuais, efetua-se um giro para dizer das condições da decisão, da autonomia do direito, da crença/aposta na discricionariedade judicial e da construção de um "senso comum teórico" que se satisfaz com essa lógica antidemocrática. Por fim, conclui-se que apenas com a vigilância dos pressupostos hermenêuticos se protegerá a fragilizada autonomia do Direito, atendendo à exigência democrática.

Palavras-chave: Autonomia do direito; Ativismo judicial; Hermenêutica filosófica.

\section{THE SOLIPSISM IN THE JUDICIAL DECISIONS PRODUCED IN THE PARADIGM OF THE PHILOSOPHY OF CONSCIOUSNESS AND THE HERMENEUTIC'S DEMOCRATIC DEMAND}

\begin{abstract}
:
This work aims to enlighten the judicial decisions issue in Brazil. Adopts, as method, the hermeneutic phenomenology to examine how to decide court cases, resulting in the adoption of certain understandings. After understanding the temporal logic that led the legal system under current conditions, makes up a spin to say the conditions of the decision, the autonomy of law, belief/commitment to judicial discretionarily and the construction of a "theoretical common sense" that is satisfied with this anti-democratic logic. Finally, it concludes that only constant vigilance of hermeneutic assumptions may protect the already fragile law's autonomy, attending democracy's demand.
\end{abstract}

Keywords: Law's autonomy; Judicial activism; Philosophical hermeneutics.

\section{INTRODUÇÃO}

O presente trabalho procurou evidenciar, nessa quadra histórica contemporânea, o reconhecimento da crise aplicacional do direito e de sua representatividade inserida na atual sociedade heterogênea e carente de efetividade de direitos como a brasileira.

\footnotetext{
${ }^{1}$ Mestranda em Direito pelo Programa de Pós-Graduação em Direito da Universidade Federal de Santa Maria (PPGD-UFSM); área de concentração: Direitos Emergentes na Sociedade Global; linha de pesquisa: Direitos na Sociedade em Rede. Possui graduação em Direito pelo Centro Universitário Franciscano (2015).

${ }^{2}$ Mestre em Direito Público, na linha de pesquisa intitulada Hermenêutica, Constituição e Concretização de Direitos, pela Universidade do Vale do Rio dos Sinos/UNISINOS. Bacharel em Direito pelo Centro Universitário Franciscano/UNIFRA. Professor do Curso de Direito do Centro Universitário Franciscano/UNIFRA
} 
À vista disto, exibir a importância de (re)discutir o problema metodológico discursivoargumentativo entranhado em nosso organismo jurídico-institucional, resultante de uma dogmática judicante alicerçada sobre a égide do esquema sujeito-objeto. Procurou demonstrar a comunicabilidade de tais elementos como catalizadores da "baixa efetividade" da Constituição Federal brasileira, causando o deslocamento da tensão decisória (como outros temas controversos) do Poder Legislativo e Executivo para o Poder Judiciário a fim de "satisfazer" às necessidades sociais, fenômeno norteado pelo paradigma judicialização, onde o Judiciário se apresenta como instrumento-solução para consumação de direitos não realizados.

Nesse cenário ocorre o ensejo do protagonismo judicial, suscitando diretamente no enfraquecimento da autonomia do direito e seus pressupostos democráticos limitadores de poder. Ora, após intensos combates a fim de conquistar direitos fundamentais através das conquistas civilizatórias nos textos legais-constitucionais em prol de um Estado Democrático e Social; como podemos ser refratários à dependência da imputação à consciência do sujeitojuiz como locus da atribuição de sentido (solipsista) no afã de alcançar a "vontade da lei" e qual o papel do direito e da dogmática jurídica neste contexto?

Destarte, se faz necessário superar esta resistência jurídico-institucional corolária do paradigma interpretativo do sujeito-juiz-protagonista, deixando o direito à mercê de um procedimento calcado na sistemática sujeito-objeto, já superado pela viragem interpretativa ontológico-linguística.

No que tange à metodologia científica, o presente trabalho acoplou uma abordagem fenomenológica (o que exclui as tradicionais formas de abordagem do conhecimento), que permite efetuar uma compreensão a partir das visões de investigador e de investigado, simultaneamente. O observador é atribuidor de sentidos, e nessa construção também recebe sentido da história. Faz e é feito, em um mesmo movimento. Sendo assim, o cientista se projeta no mundo a partir de uma condição, situação inexorável. Daí a utilização da terminologia "ser-no-mundo" de Heidegger. O próprio Dasein, que significa dois movimentos autocompostos: o homem que desvela significados do mundo, e o mundo que desvela significados do homem.

Posto isso, ao desenvolvimento da temática proposta.

1 A INFLUÊNCIA DO SEGUNDO PÓS-GUERRA COMO FENÔMENO ENSEJADOR DO “CONSTITUCIONALISMO DIRIGENTE” PULSIONANDO UM REARRANJO JUDICANTE E SUA RECEPÇÃO TARDIA NO ÂMBITO 


\section{BRASILEIRO}

Para percorrer sobre o solo fenomenológico ${ }^{3}$ incutido na matriz teórica alinhada pela Crítica Hermenêutica, através de um afinamento dedicado às consequências da viragem linguístico-ontológica para o Direito e sua existência na linguagem da jurisdição constitucional $^{4}$, abre-se a clareira da ultrapassagem da filosofia da consciência, posicionando o lugar de fala a fim de compreender a temática proposta, sob pena de sucumbir dentro da alienação ${ }^{5}$ Heideggeriana, uma vez que o indivíduo é dotado de historicidade desde sempre e é impossível separar este atributo do todo da existência humana.

Ilustrando muito bem acerca deste necessário diagnóstico sobre o que a história tem a rememorar, J.J Gomes Canotilho ${ }^{6}$ alerta que um direito ex cathedra, ou seja, um direito reduzido a teorias abstratas, esquece que os problemas tanto do indivíduo quanto da polis se situam no terreno da experiência humana e não nas alturas abstratas das teorias que esquecem o lugar das coisas e o mundo dos sujeitos. Nesse ínterim, o que no contexto contemporâneo se apresenta como uma eclosão da intensificação jurisdicional, vislumbrada na perspectiva brasileira, já foi vivenciada pelos Estados Unidos, que, em razão disso, desde a instituição do controle de constitucionalidade (judicial review) em 1803, gerou múltiplos acervos literários questionando as atribuições, limites e competências do Poder Judiciário ${ }^{7}$, demonstrando a antecipação do respectivo debate no solo estadunidense quando aferido o brasileiro.

No Brasil, a modernidade é tardia e arcaica ${ }^{8}$. A carga semântica desta premissa soa de maneira retumbante na realidade contemporânea do indivíduo brasileiro. Sob um olhar atento ao passado, verifica-se que países da América Latina, como o Brasil, eram refratários para o que era produzido na tradição anglo-saxã. Como bem assinala o jurista colombiano Diego Eduardo López Medina, por muito tempo viveu-se sob o manto de um formalismo na

\footnotetext{
${ }^{3}$ Heidegger reelabora a relação entre "compreensão" e "interpretação", em miúdos, onde aclara que "interpretar não é tomar conhecimento do que se compreendeu, mas elaborar as possibilidades projetadas no compreender". HEIDEGGER, Martin. Ser e Tempo. Petrópolis, RJ: Vozes, 2008, p. 209.

${ }^{4}$ MOTTA, Francisco José Borges. Levando o direito a sério: uma crítica hermenêutica ao protagonismo judicial. 2. ed. rev. e ampl. Porto Alegre: Livraria do Advogado, 2012.

5 Em Heidegger este é o sentido da alienação: "uma tentativa de fugir da condição histórica, que é a de ter um passado irremissível e um futuro que não tem saída." STEIN, Ernildo. Racionalidade e Existência: O ambiente Hermenêutico e As Ciências Humanas. $2^{\mathrm{a}}$ ed. Unijuí, 2008, p.37

${ }^{6}$ CANOTILHO, José Joaquim Gomes. Direito Constitucional e Teoria da Constituição. $3^{\text {a }}$ ed. Coimbra, 2006, p.16.

7 TASSINARI, Clarissa. Jurisdição e Ativismo Judicial: Limites da atuação do Judiciário. Porto Alegre: Livraria do Advogado Editora, 2013, p.40.

${ }^{8}$ A expressão é de STRECK, Lenio Luiz. Hermenêutica Jurídica e(m) crise. $8^{a}$ ed. Livraria do Advogado, 2009, p.24. Este ponto será objeto de análise específica adiante.
} 
aplicação do direito (compreendido por um prisma que reduzia o direito à lei), legado do direito privado europeu ${ }^{9}$. A propósito, o positivismo jurídico, enquanto cartilha epistemológica assentada no predomínio da lei no intento de atribuir cientificidade ao direito foi (e continua sendo) o principal modo de fundamentar o conhecimento jurídico ${ }^{10}$.

Neste enredo, admitindo o reconhecimento de um olhar tardio para as recepções ideológico-jurisdicionais no cenário brasileiro, o pós-Segunda Guerra Mundial vem trazer o surgimento da noção de "constitucionalismo dirigente" desta forma, mudanças na organização política e jurídica global.

O período decorrente à Segunda Guerra Mundial foi tido como era de um novo desabrochar do Direito no mundo todo. Fato este, porque, para que fossem superadas as atrocidades praticadas durante a existência dos regimes autoritários, era impreterível que se rompesse com as amarras de toda a estrutura legislativa que lhes atribuía legitimidade através da maculada obrigação de obediência a um formalismo rigoroso, de mera observação do procedimento adequado para a criação de leis ${ }^{13}$. Destarte, a cessação desta Guerra serviu de motor para um rearranjo institucional que tinha como fito a garantia de direitos fundamentais constitucionalmente assegurados, esculpindo, assim, a transição do que se conhecia por Estado Legislativo de Direito para um Estado Constitucional de Direito $^{14}$.

Doravante, em meio destes fenômenos histórico-institucionais originários do solo europeu, emerge a noção de constitucionalismo democrático, ensejando, inclusive, uma nova análise sobre o conceito de Direito, onde a própria justiça, de legal-formal, passa a legal-material ${ }^{15}$. Isto é, a nova ótica de conceber o fenômeno jurídico, que passa ser configurado sob uma concepção de materialidade (de substancialidade) e engendrado através da inclusão de dois elementos centrais: o reconhecimento da força normativa da Constituição e de seu caráter cogente, que condiciona materialmente a legalidade; e da

\footnotetext{
${ }^{9}$ LÓPES MEDINA, Diego Eduardo. Teoría impura del derecho: La transformación de la cultura jurídica latino-americana. Bogotá: Legis, 2004.

10 Desde o positivismo exegético, normativista e todas suas adaptações ao decorrer dos tempos, foi uma postura epistemológica muito influente no modo de como compreender o direito, surtindo consequências no plano jurídicoinstitucional até hoje. Para este tema, ver o artigo de Lenio Streck: Aplicar a letra da lei é uma atitude positivista? Revista Novos Estudos Jurídicos - Eletrônica, vol. 15, n.1, p.158-173. Disponível em http://www.univali.br/seer /index.php/nej/article/view/2308. Acesso em: 20 abr.2015.

${ }^{11}$ CANOTILHO, José Joaquim Gomes. Constituição dirigente vinculação do legislador. Contributo para a compreensão das normas constitucionais programáticas. $2^{\mathrm{a}}$ ed. Coimbra: Coimbra Editora, 2001, p.27.

${ }^{12}$ Verificar "pretensão de eficácia". HESSE, Konrad. A Força Normativa da Constituição. Porto Alegre: Sérgio Antônio Fabris, 1991, p. 14-5.

${ }^{13}$ TASSINARI, Clarissa. Jurisdição e Ativismo Judicial: Limites da atuação do Judiciário, op. cit., p.40.

${ }^{14}$ FERRAJOLI, Luigi. Sobre los derechos fundamentales. Tradução de Miguel Carbonell. In: CARBONELL, Miguel (Org.). Teoría del neoconstitucionalismo: ensayos escogidos. Madrid: Trotta, 2007, p.72.
} 
incorporação de novas garantias, novos direitos aos cidadãos, com seus respectivos meios (instrumentos) assecuratórios ${ }^{16}$.

Concernente a este ambiente de movimento constitucionalizante engendrado na Europa pós-Segunda Guerra Mundial, apesar da considerável assimilação global, faz-se mister rememorar que os países da América Latina eram acometidos sob a égide de regimes ditatoriais, surtindo, portanto, um entrave à recepção desse movimento. Posto isto, afirma-se que houve um hiato temporal quanto à admissão de uma nova forma de pensar o Direito em solo brasileiro, ocorrendo apenas com o processo constituinte em 1987-88, após a ruptura desses regimes ${ }^{17}$.

Não obstante o período de restrição, tanto social quanto ideológico-institucional, que revestiu o Brasil durante esta época, a partir da promulgação da Constituição de 1988 -a chamada Constituição Cidadã- o constitucionalismo brasileiro começou a introduzir os avanços produzidos no continente europeu. Neste quadro de recepção tardia, teve imenso valor a proposição teórica do renomado José Joaquim Gomes Canotilho, alçada no livro “Constituição Dirigente e Vinculação do Legislador", no qual aprofundou a tese do jurista alemão Peter Lerche (dirierende Verfassung) de $1961^{18}$, o que a posteriori ficou conhecido como "constitucionalismo dirigente". A vista disso, Canotilho teve o afã de demonstrar o papel estratégico assumido pelas constituições, de modo que, ao "utilizar-se da expressão 'constituição dirigente', pretendeu-se [...] afirmar a força actuante do direito constitucional". ${ }^{19}$ Assim, ao panorama de Estado de Direito foi agregada uma substancialidade extraída do próprio texto constitucional, de modo que a constituição passa a ser um "meio de direção social" e "uma forma "racionalizada' de política"20.

Esta forma de conferir ao texto constitucional um atributo catalizador de todos os atos do Estado deu novo fundamento ao direito constitucional ${ }^{21}$, fazendo, igualmente, com que a jurisdição, pelo prisma deste entendimento de irradiação constitucional, direcionasse a novos rumos, os quais estariam voltados à concretização das promessas constitucionais .

\footnotetext{
${ }^{15}$ GARCÍA-PELAYO, Manuel. As transformações do estado contemporâneo. Tradução de Agassiz Almeida Filho. Rio de Janeiro: Forense, 2009, p.14.

${ }^{16}$ STRECK, Lenio Luiz. Hermenêutica Jurídica e(m) crise. $8^{\mathrm{a}}$ ed. Livraria do Advogado, 2009, p.

${ }_{17}^{17}$ TASSINARI, Clarissa. Jurisdição e Ativismo Judicial: Limites da atuação do Judiciário, op. cit., 40.

18 Ibidem.

${ }^{19}$ CANOTILHO, José Joaquim Gomes. Constituição dirigente vinculação do legislador. Contributo para a compreensão das normas constitucionais programáticas. $2^{\mathrm{a}}$ ed. Coimbra: Coimbra Editora, 2001, p.27.

${ }^{20}$ Ibidem, p.48

${ }^{21}$ J.J Gomes Canotilho projeta a constituição dirigente da seguinte forma: "Trata-se, pois, de uma lei fundamental não reduzida a um simples instrumento de governo, ou seja, um texto constitucional limitado à individualização dos órgãos e à definição de competências e procedimentos da ação dos poderes públicos (...) A Constituição comandaria a acção do Estado e imporia aos órgãos competentes a realização das metas programáticas estabelecidas”. (CANOTILHO, José Joaquim Gomes. Direito Constitucional e Teoria da Constituição. Coimbra: Almedina, 2000, p.17).
} 
Com a inserção da democracia como elemento fulcral, por excelência, amalgamada no modelo Constitucional, as feições do Estado tomaram nova forma e ordens constitucionais exsurgiram desse período. Assim como o desígnio democrático se baseia na percepção de soberania popular como fonte última do poder político, o âmago que constitui o constitucionalismo é a limitação de poder $^{22}$. Desse modo, diz-se que o constitucionalismo é essencialmente contramajoritário, evitando que ideais político-axiológicos momentâneos possam pôr em risco os direitos de minorias.

É desse liame indissolúvel que se ergue a ideia de um "plus normativo" do Estado Democrático de Direito. Transcende-se uma mera classificação de Estado ou de uma variante de sua evolução histórica, pois o Estado Democrático de Direito faz um compêndio das fases anteriores, compilando a construção das condições de possibilidades para suprir as lacunas das fases anteriores, tendo como protagonista a necessidade do resgate das promessas da modernidade, tais como a igualdade, justiça social e garantia dos direitos humanos fundamentais ${ }^{23}$.

Em contrapartida como bem menciona Gilberto Bercovici, "a concepção de constituição dirigente ligada à defesa da mudança da realidade pelo direito" ${ }^{24}$, ou seja, este modelo de promessas -que impõe ao Estado a incumbência de resgatar o imenso débito social- se apresentou como um solo fértil e atrativo, o qual ensejou a transferência do foco de conflito social para o Poder Judiciário. Que assume papel transformador do status quo e efetivador de uma igualdade substancial; onde a jurisdição constitucional possui o condão de salvaguardar tanto os direitos previstos constitucionalmente quanto o controle dos atos estatais.

\section{A AMPLIAÇÃO DA LITIGIOSIDADE COMO UM FENÔMENO DAS SOCIEDADES CONTEMPORÂNEAS E SEUS EFEITOS NO PLANO JUDICANTE DEFRONTE À POSTURA DO ESTADO, ENQUANTO SIGNO GARANTIDOR DA PROMESSA DEMOCRÁTICA}

O aparecimento dos ideais constitucionais oriundos do segundo pós-guerra remodelou consideravelmente a essência do constitucionalismo em escala global. Ao incorporar direitos sociais e imputar objetivos programáticos ao Estado suscitaram uma

\footnotetext{
${ }^{22}$ Ibidem, p. 27.

${ }^{23}$ STRECK, Lenio Luiz. Hermenêutica Jurídica e(m) crise. $8^{\text {a }}$ ed. Livraria do Advogado, 2009, pg. 37.
} 
maior espessura normativa nas constituições, que passaram a ser percebidas não apenas como um elemento de sistematização institucional, mas também a influenciar na política governamental a partir de um prisma de irradiação constitucional através do sistema jurídico. À vista disso, esses mecanismos jurídicos viabilizaram mudanças significativas alicerçadas por dois artifícios: por uma perspectiva, ampliou-se a listagem de direitos sociais, com o objetivo de proporcionar uma política de bem-estar; de outra, determinou o encargo de tornar esta programaticidade, de fato, efetiva ${ }^{25}$.

Segundo Galeano: “A história é um profeta com o olhar voltado para trás: pelo o que foi, e contra o que foi, anuncia o que será” ${ }^{26}$, corroborando a premissa de Galeano, a sociedade ajudou tonificar a concepção de Estado forte, calcada no direito positivo e no normativismo-dirigente, focalizando dar respostas às demandas da sociedade moderna, que estava marcada pela indeterminação e insegurança, oriundas do processo de ruptura com o modelo jusnaturalista (e seus "valores absolutos a priori, portanto, estáticos e fora do tempo"). ${ }^{27}$ Doravante, ao decorrer dos anos, a sociedade desempenhou o papel de personagem e espectador de ininterruptas transformações sociais, sendo que globalização, transnacionalização, novos direitos, dentre outros temas, passaram a ser o eixo de um novo modelo de sociedade complexa em "tempos interessantes" 28.

Paradoxalmente, ainda que as atribuições jurídico-institucionais imputadas ao Estado reforçassem uma concepção de "entidade forte", frente ao quadro de latentes transfigurações nos diversos âmbitos, torna-se perceptível o efeito de certa fragilização da esfera estatal, de modo que a sociedade se apresenta inclusa em uma intensa litigiosidade, motivada através de demandas sociais imbuídas do desejo de efetivação de promessas que lhe foram chanceladas, como modo de resgatar o compromisso firmado pelo Estado Democrático de Direito. Posto isso, os cidadãos passam a transvestir uma postura conduzida ao conflito, à requisição de efetivação de direitos pela via do litígio judicial, o qual passa a protagonizar o cenário de solução de grande parte das contendas jurídicas.

Este atributo comportamental que a comunidade contemporânea passou a adotar acaba desaguando no que Luiz Werneck Vianna denomina de “judicialização das relações

\footnotetext{
${ }^{24}$ BERCOVICI, Gilberto. Ainda faz sentido a constituição dirigente? Revista do Instituto de Hermenêutica Jurídica: 20 anos de constitucionalismo democrático - e agora? Porto Alegre, vol. 1, n. 6, p.149-162. 2008, p.151.

${ }^{25}$ CAPPELLETTI, Mauro; GARTH, Bryant. Acesso à Justiça. Tradução de Ellen Gracie Northfleet. Porto Alegre. Sérgio Antônio Fabris, 2002, p. 5-7.

${ }^{26}$ Trecho extraído de GALEANO, Eduardo. Veias Abertas da América Latina. Tradução de Sergio Faraco. Porto Alegre: L\&PM, 2010, p. 15.

${ }^{27}$ ROCHA, Leonel Severo. Da epistemologia jurídica normativista ao construtivismo sistêmico. In: SCHWARTZ, Germano; CLAM, Jean. Introdução à teoria do sistema autopoiético do direito. Porto Alegre: Livraria do Advogado, 2005, p. 12-15.
} 
sociais", ilustrada na expansão invasiva com que o direito entranhou na organização da vida social. ${ }^{29}$ Ainda neste tópico, se faz mister aclarar quanto à normalidade das conflituosidades sociais acentuadas, haja vista que o contexto atual é imbuído num regime democrático, por excelência, tendo como característica a ampla distribuição de poder (difusa) ${ }^{30}$. Sendo assim, havendo diversos centros de poderes, há uma maior aparição de contentas, que, na sociedade contemporânea, recaem para que o Judiciário solucione.

Observando tal panorama, cabe apontar tocante à modificação estrutural no modo de compreender como tais direitos são absorvidos por esta sociedade complexa. Nesse sentido, há uma eclosão de imposições coletivas e interesses difusos, adjetivos de uma sociedade em que a "produção, o consumo e a distribuição apresentam proporções massificadas" 31 , dessa maneira, torna-se perceptível a exigência da prestação jurisdicional pela massificação, trazendo a ideia de pluralismo para o eixo da atuação das organizações sociais. Produto disso edifica-se um contexto paradoxal, haja vista que se de um aspecto o atual ambiente implementou a possibilidade de tutelar direitos difusos e coletivos, de outra banda, a busca por sua efetivação predominantemente se dá através do pleito litigioso individual, desta forma, apresenta-se um vasto conjunto de ações singulares intentando à tutela de direitos

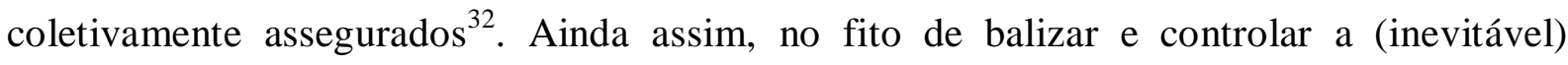
judicialização, o arranjo jurídico-institucional se aparelha por meio de alguns instrumentos a partir da extensão no conceito de acesso à justiça, tal qual a criação, por parte dos tribunais, do alcunhado julgamento processual em bloco (a fim de suprir a massificação de demandas com pretensões semelhantes), ${ }^{33}$ como a criação dos juizados especiais, marcados por um procedimento menos formal, e a própria incorporação da antecipação de tutela, como mecanismo de satisfação do direito focando a celeridade. ${ }^{34}$

O amálgama de todas essas modificações - anseios de uma sociedade-multiface, cultura da litigiosidade, massificação da sociedade e redefinição do acesso à justiça desembocam seus efeitos no flúmen da judicialização. Nesse contexto, cabe incluir a

\footnotetext{
${ }^{28}$ Expressão usada como título na obra Hobsbawn, Eric. Tempos interessantes: uma vida no século XX. São Paulo: Companhia das Letras, 2002.

${ }^{29}$ VIANNA, Luiz Werneck. et al. A judicialização da política e das relações sociais no Brasil. Rio de Janeiro: Revan, 1999. p.149.

${ }^{30}$ FERRAJOLI, Luigi. Derechos y garantias: La ley del más débil. Traducción de Perfecto Andrés Ibáñez y Andrea Greppi, 3a. ed. Madrid, Trotta, 1999, p. 85.

${ }^{31}$ CAPPELLETTI, Mauro. Acesso à justiça. Op. cit., p.43.

${ }^{32}$ Ibidem, p. 45.

33 Sendo fonte de fortes críticas por Lenio Streck, os intitulados julgamentos em bloco esculpem a típica preocupação com a efetividade quantitativa em detrimento de uma efetividade qualitativa, decorrente do fenômeno da judicialização. Para tanto, ver: STRECK, Lenio Luiz. Verdade e consenso: constituição, hermenêutica e teorias discursivas. $4^{\mathrm{a}}$. Ed. São Paulo: Saraiva, 2011, p.371.

${ }^{34}$ CAPPELLETTI, Mauro. Acesso à justiça. Op. cit., p.12.
} 
concepção de reforma processual, a qual Dierle Nunes denomina de "simplificação procedimental", oriunda do que no âmbito do processo civil emergiu como "socialismo processual". ${ }^{35}$ Dessa forma, por esta via, a questão do acesso à justiça passou ser afiliada a um reforço nas atribuições jurídico-institucionais, à ênfase nos pronunciamentos de ofício, à possibilidade de julgamento ultra petita, ou seja, culminando não só em uma simplificação dos procedimentos ou pela tutela de direitos coletivos e difusos, como também pelo aumento da ingerência dos juízes ${ }^{36}$. Ainda é possível inferir, inclusive, que interpretações equivocadas tangentes ao entendimento de acesso à justiça, concebido como eficiência judicial, acabaram catalisando um imaginário que tonificou ainda mais o papel do Judiciário como instituição hábil a solucionar os problemas da sociedade, fomentando as ranhuras do que adiante será abordado como um ativismo judicial transvestido de solução.

\section{A ASCENSÃO JURISTOCRÁTICA E O ENFRAQUECIMENTO DA AUTONOMIA DO DIREITO: UMA REFLEXÃO SOBRE A DEMOCRACIA E A DISCRICIONARIEDADE JUDICIAL}

Materializando (literariamente) com ardileza, o filósofo Jean-François Lyotard realça que o tempo se torna mais veloz na modernidade, especialmente no pós-guerra, ao desvelar a verdade de que "o desenvolvimento impõe que se ganhe tempo. Andar depressa é esquecer depressa, dispor apenas a informação útil no momento, tal qual acontece com a "leitura apressada"37. Tal consideração é ainda mais intensificada no âmbito jurídico contemporâneo em que a sociedade é cada vez mais dinâmica fomentada pelas intercomunicações e as distâncias das informações cada vez mais reduzidas. Contudo, com o avanço também emerge a carência de assimilação de fatos sociais marcados pelo efêmero. A liquidez institucional denunciada pelo filósofo Zygmunt Bauman, infere que as “organizações sociais [...] não podem manter sua forma por muito tempo (nem se espera que o façam), pois se decompõe e se dissolvem mais rápido que o tempo que leva para moldá-las e, uma vez reorganizadas, para que se estabeleçam". ${ }^{38}$ Para além dessa constatação acerca do dinamismo social contribuindo para ascensão do Judiciário a fim de suprir as demandas

\footnotetext{
${ }^{35}$ A ideia do movimento, que teve como berço os países do Leste Europeu, tinha como objetivo alcançar uma harmonização do processo civil com os Estados de bem-estar, resultando em uma maior intervenção do magistrado, visando uma alegada aplicação social e política do direito. TASSINARI, Clarissa. Jurisdição e ativismo judicial. Op. cit., p.48.

${ }^{36}$ NUNES, Dierle José Coelho. Processo jurisdicional democrático. Curitiba: Juruá, 2011, p.116-124.

${ }^{37}$ LYOTARD, Jean-François. O Inumano: considerações sobre o tempo. Tradução de Ana Cristina Seabra e Elisabete Alexandre. Lisboa: Estampa, 1990, p.10.

${ }^{38}$ BAUMAN, Zygmunt. Tempos líquidos. Tradução de Carlos Alberto Medeiros. Rio de Janeiro: Jorge Zahar, 2007 , p.7.
} 
sociais, edifica-se um embate entre o velho modelo (sentido comum teórico - crise de paradigma dupla face) e o novo retrato de uma jurisdição jurídico-democrática (substancialização da Constituição Federal), o que obsta/dificulta o "acontecer" da Constituição.

À evidência, o quadro jurídico-institucional brasileiro se encontra imerso em uma crise aplicacional do direito e sua (ir)representatividade. Lenio Streck há muito já denuncia a "baixa efetividade" Constitucional, uma vez que "de um lado percebe-se uma sociedade carente de realização de direitos e, de outro, uma Constituição Federal que garante estes direitos da forma mais ampla possível. Este é o contraponto.” Posto isto, faz-se mister a ressonante indagação: qual é o papel do Direito e da dogmática jurídica neste contexto? A Constituição forjada no paradigma liberal-individualista-normativista está apta a superar a "tradição inautêntica" do Direito? Ora, frente à inercias do Poder Executivo e um Legislativo ineficaz, o Judiciário se apresenta como possível locus de realização dos direitos Constitucionais, comprometendo, desta forma, um dos alicerces sustentadores do modelo neoconstitucionalista: a democracia ${ }^{39}$. Assim sendo, é fundamental fitar atentamente à importância de (re)discutir o problema metodológico discursivo-argumentativo concebido na esfera judicante.

Não obstante a edificação da disfuncionalidade do Estado, do Direito e da própria Constitucição, o paradigma liberal-individualista-normativista catalisa a concepção linear dos juristas na contemporaneidade, a qual se apresenta como responsável por esta considerável fragilização jurídico-institucional. Fruto disto, há uma maleabilidade tocante os direitos individuais, políticos e sociais penosamente conquistados pela sociedade. Vivese em um cenário marcado pela desterritorialização, desregulamentação e desconstitucionalização, ao ponto que a própria Constituição tem sido vista como um óbice para os avanços contemporâneos (mercado, economia, efetivação material). ${ }^{40}$

Frente a este cenário complexo (d)e crise funcional, faz-se urgente questionar o papel do Direito e dos juristas, sobretudo, no que se refere à atribuição de sentido aos conteúdos normativo-constitucionais, de modo que seja (re)pensada a postura do sujeito-juiz, suas práticas, seu discurso, seu modo de fazer/interpretar o Direito. ${ }^{41}$ Veja-se, a cultura dogmática-jurídica brasileira, calcada na concepção epistemológica positivo-normativista,

\footnotetext{
${ }^{39}$ STRECK, Lenio Luiz. Hermenêutica Jurídica e(m) crise. Op. cit., p.35.

${ }^{40}$ SALDANHA, Jânia Maria Lopes. Constituir a Constituição para a cidadania: A Compreensão e a Linguagem na Nova Crítica do Direito Afastando os Mitlaufers Jurídicos. In: Olhares Hermenêuticos sobre o Direito: em busca de sentido para os caminhos do jurista. Org. Douglas Cesar Lucas - Ijuí: Unijuí, 2007, p. 64.

${ }^{41}$ Ibidem.
} 
preocupada essencialmente pela sistematização dos procedimentos jurídicos, reforça-se o olhar compenetrado aos métodos e critérios de aprendizagem no intuito de objetificar as normas jurídicas, como se fosse alcançável desvelar (e aprisionar) seu "real sentido". Ora, a interpretação, assim, não é uma intromissão do sujeito que desnuda as verdades obnubiladas no objeto, mas é, sim, o instante de explicitação do compreender, daquilo que se encontra à disposição e que é desvelado pela compreensão. ${ }^{42}$

Inserindo-se neste modo de observação, se desvela que a crise discursivoargumentativa do Direito não é somente uma deficiência de sua estrutura tradicional, mas uma crise da integração de seus pressupostos dogmáticos para atuar dentro da globalização, e por consequência, culminando naquilo que Lenio Streck denominou de "crise dupla face" 43 e"baixa constitucionalidade" 44 (ainda) subserviente ao paradigma da filosofia da consciência imergida em seu caráter metafísico (reificante). Desta maneira, a modernidade, ao romper com a forma política medieval, e com o jusnaturalismo transcendente, "enfrenta pela primeira vez, a problemática do controle das decisões" ${ }^{\text {"45 }}$.

Ou seja, as relações entre tempo e Direito. Dentro deste aspecto, se põe saltante a herança do formalismo imbricado ao conjunto de ritos e procedimentos burocratizados e impessoais, justificados em nome da certeza jurídica e "segurança do processo", calcado no molde epistemológico liberal-individualista-normativista de produção do Direito ${ }^{46}$.

À vista disto, a objetificação do Direito - denunciada pela hermenêutica filosófica põe à míngua a percepção do jurista e o enclausura em uma limitação metodológica, culminando no que Lenio Streck denominou "baixa compreensão do sentido da Constituição [que] acarreta uma baixa constitucionalidade" ${ }^{\text {47 }}$. Desse modo, faz-se pífio sustentar epistemologicamente que a Constituição produzirá significados além dos sentidos que a (pré)compreensão fornece, haja vista que esta deve ser percebida tal qual um percurso a ser percorrido, um programa a ser cumprido na conjuntura das possibilidades da vida política, econômica e social brasileira. Seu corpo textual espelha escolhas de um específico tempo,

\footnotetext{
${ }^{42}$ STRECK, Lenio Luiz. Hermenêutica Jurídica e(m) crise. Op. cit., p.57.

43 Nesse sentido clarifica: "de um lado, uma crise de modelo de Direito (preparado para o enfrentamento de conflitos interindividuais, o Direito não tem condições de enfrentar/atender as demandas de uma sociedade repleta de conflitos supraindividuais); de outro, a filosofia da consciência” STRECK, Lenio. Jurisdição Constitucional e Hermenêutica: Uma Nova Crítica do Direito. Porto Alegre: Livraria do Advogado, 2002, p.32.

${ }^{44}$ Nesta análise Streck agrega outros elementos, quais sejam, o "simulacro do Estado Social", "prevalência do paradigma liberal-racionalista-iluminista no Direito", "fenômeno da globalização", "políticas neoliberais".

${ }^{45}$ Ver: ROCHA, Leonel Severo. Direito, Cultura Política e Sociedade. In: Rocha, Leonel Severo; STRECK, Lenio. Anuário do programa de Pós Graduação em Direito da Unisinos. n.II, São Leopoldo: Unisinos, 2000.

${ }^{46}$ Ibidem, p. 74.

${ }^{47}$ Ibidem.
} 
de uma demarcada compreensão sobre a Política, Estado, Economia, resguardadas por um regime democrático.

Desse modo, a Constituição não pode(ria) ser tomada como objeto ou repositório de sentidos que serão descobertos pelo condão metodológico de técnicas interpretativas. Ela apresenta uma gramática social e jurídica que necessita ser compreendida com um existencial que compõe realidade ao projetar possibilidades comprometidas com o Estado Democrático de Direito $^{48}$. Destarte, interpretar a Constituição não se trata de um exercício de pura técnica, de procedimento objetificadores, por isso, é preciso compreender esse paradigma através da filtragem hermenêutica filosófica objetivando blindar as maneiras discricionárias/solipsistas (que unificam todas as formas de positivismo) de conceber o Direito no seu mundo prático, sob pena de ensejarmos um ativismo judicial institucionalizado $^{49}$. Nesta análise, o elemento interpretativo que caracteriza mais propriamente a experiência jurídica pode, e deve ser explorado fenomenologicamente.

É possível oferecer limites ou anteparos à atividade interpretativa, na medida em que o direito não é concebido a partir de um reducionismo fático. Compreender a maneira que o sujeito-jurista interpreta é uma (necessária) questão de controle democrático das decisões, ${ }^{50}$ superando, desta forma, a chaga do "senso comum teórico do direito" tão criticado por Streck, no afã de ser enfrentado a "não superação do positivismo jurídico naquilo que é seu principal elemento - a discricionariedade, sustentada por sua vez, no solipsismo do sujeito da modernidade" 51

Destarte, é na esteira do Constitucionalismo Contemporâneo, com foco principal para o problema do ativismo judicial, que se pode inferir, no tocante ao nosso contexto jurídico atual, o traço de três símbolos óbices: o "enfrentamento das recepções teóricas equivocadas (e de suas mixagens)", a superação da discricionariedade judicial e a preservação da autonomia do direito.

\section{O ENFRENTAMENTO DA DISCRICIONARIEDADE JUDICIAL: RESPONSABILIDADE HERMENÊUTICA FRENTE AO DIREITO ENQUANTO CONCEITO INTERPRETATIVO}

\footnotetext{
${ }^{48}$ LUCAS, Douglas César. Hermenêutica Filosófica e os limites do acontecer do direito numa cultura jurídica aprisionada pelo "procedimentalismo metodológico". In: LUCAS, Douglas César (Org.) Olhares hermenêuticos sobre o direito. Ijuí: Unijuí, 2007, p.32.

${ }^{49}$ STRECK, Lenio Luiz. O que é isto - decido conforme minha consciência? Porto Alegre: Livraria do Advogado, 2010,

${ }^{51}$ STRECK, Lenio Luiz. Hermenêutica Jurídica e(m) crise. Op. cit., p. 104.
} 
Ao aperceber as ramificações concernentes ao modo de compreender a razão pela qual a discricionariedade-solipsista passou a entranhar no campo da interpretação/aplicação dos direitos no Brasil pode perpassar por vários aspectos fenomenológicos, mas qualquer um deles irá adentrar em um mesmo objeto: o positivismo jurídico. Nesse ínterim, seja remetido ao que Hans Kelsen e Herbert Hart deixaram de legado teórico (considerados positivistas mais influentes), seja pela interpretação que as teorias neoconstitucionalistas (e outros tipos de pós-positivismos) fizeram acerca do que apresentaram estes doutrinadores, Tassinari é reta quanto ao amálgama desses fatos conduzirem diretamente à discricionariedade positivista ${ }^{52}$.

Kelsen, ao criar sua teoria pura do direito (positivismo normativista), ${ }^{53}$ sob um prisma descritivo, elabora uma tese com o fito de atribuir cientificidade ao Direito, principalmente por meio de sua separação das demais áreas da esfera social (Moral, Política e Economia). Nessa banda, faz-se mister identificar que na esfera em que aborda a aplicação das leis, infere três importantes afirmações: primeiro, que a interpretação por órgãos jurídicos é ato de vontade (e não ato de conhecimento do direito positivo); segundo, que ao identificar espaço para alguma atitude cognoscitiva, ela se dá em relação à aptidão de incidência de outras normas (como de moral e de justiça); e terceiro, ao conhecido jargão de que aplicação se dá de modo discricionário dentro da moldura da lei (como também fora dela) ${ }^{54}$, criando direito.

Registre-se, que, ao abordar o tema da interpretação, Kelsen não se preocupa com uma teoria verossímil na maneira de se decidir (visto que para ele, este é um problema de política jurídica), motivo que no plano da aplicação do direito, acaba por admitir a moral (inserida no campo do relativismo). ${ }^{55}$ Consoante o que Lenio Streck aclara as teorias que se autodenominam como neoconstitucionalistas (ou pós-posititivistas) conceberam de maneira equivocada o positivismo kelseniano, ou seja, não compreenderam a dupla camada de sua proposta, referente à ciência e da aplicação do direito ${ }^{56}$, ao passo que visavam superar tal

\footnotetext{
${ }_{53}^{52}$ TASSINARI, Clarissa. Jurisdição e Ativismo Judicial: Limites da atuação do Judiciário, op. cit., p.91.

${ }^{53}$ Kelsen, ao desenvolver uma metateoria objetivando distinguir lei e Direito, propondo, assim, uma ciência do direito à diferença do próprio direito, bem como uma metalinguagem distinta de seu objeto. STRECK, Lenio Luiz. Hermenêutica Jurídica e(m) crise. Op. cit., p. 335.

${ }^{54}$ KELSEN, Hans. Teoria pura do direito, op. cit., p.248.

${ }^{55}$ Em Kelsen, a ciência jurídica é posta em perigo quando não se diferencia Direito de Moral, visto que, para ele, não há como determinar um elemento moral. Sendo assim, a moral estaria inserida num contexto relativo e incerto, fato pelo qual a teoria pura objetivava suprimir para que fosse possível a edificação de uma epistemologia do Direito. Ibidem, 47-49.

${ }^{56}$ Indicando as consequências sob o errôneo pretexto de que "os juízes não são mais boca da lei", os princípios passam a ser concebidos como "era da abertura interpretativa" e "era da criação judiciária" em STRECK, Lenio Luiz. O que é isto decido conforme minha consciência? Op. cit., p. 90-91.
} 
postura - achando-se que estivera ultrapassando o positivismo exegético - por via da dilatação dos poderes jurisdicionais, servindo como subterfúgio pró solipsismo judicial.

Ao atentar que em Kelsen a decisão se dá como um ato de vontade, na qual o juiz, imbui-se de discricionariedade, para Hart (considerado positivista moderado por não defender a separação entre direito e moral), o sujeito-julgador possui o poder de escolha. Ainda que Hart tenha confrontado com vigor o realismo jurídico de Oliver Wendel Holmes (no que toca à questão da discricionariedade judicial, ficando amenizada, nesse sentido, a defesa de um sistema de regras), ele admite que as regras integradas no sistema jurídico possuem uma textura aberta, incutindo "zonas de penumbra",57, dando azo para o intérprete escolher possibilidades de aplicação (principalmente nos hard cases). Aliado a isso, existe o problema paradigmático de imputar à consciência do sujeito-juiz o locus da atribuição de sentido (solipsista), no fito de alcançar a "vontade da lei" de uma perspectiva de total dissonância com os paradigmas de Estado, sociedade do modelo normativo constitucionalizado sob a forma de Estado Democrático de Direito ${ }^{58}$.

Frente ao quadro contemporâneo (de alta judicialização) que se apresenta - ausência de cumprimento da Constituição, mediante a omissão dos poderes públicos, que não efetivam as devidas políticas públicas determinadas pelo pacto constituinte -, a via judiciária se edifica como um instrumento possível para suprir a "baixa efetividade" Constitucional. ${ }^{59}$ Por outro lado, é necessário clarificar que, na sustentação desse imaginário jurídico prevalecente, encontra-se (como já dito) disseminado ainda o paradigma epistemológico da filosofia da consciência - calcada na lógica do sujeito cognoscente, onde as formas de vida e relacionamentos são reificadas e funcionalizadas, ficando tudo comprimido nas relações sujeito-objeto (como bem denuncia Habermas) - carente e/ou refratária à viragem linguística ${ }^{60}$. Posicionar-se a favor dessas proposições é acreditar que o conhecimento deve estar fundado em estados de experiência interiores e pessoais, não se conseguindo estabelecer uma relação direta entre esses estados e o conhecimento objetivo de algo para além deles.

\footnotetext{
${ }^{57}$ Ibidem.

58 Nessa esteira, Lenio adverte: "Combater a discricionariedade, o ativismo, o positivismo fático etc. - que, como se sabe, são algumas das várias faces do subjetivismo - quer dizer compromisso com a Constituição e com a legislação democraticamente construída, no interior da qual há uma discussão, no plano da esfera pública, das questões ético-morais da sociedade". Ibidem, p. 110 (grifos do autor).

${ }^{59}$ STRECK, Lenio Luiz. Hermenêutica Jurídica e(m) crise. op. cit., p. 89.

${ }^{60}$ Ibidem, p. 103.
} 
Uma boa ilustração de como se dá esse arquétipo de aplicação jurisdicional reside no trecho do voto do Ministro Humberto Gomes de Barros, em conhecido julgamento no Superior Tribunal de Justiça ${ }^{61}$.

Verifica-se que o direito não é e não pode ser aquilo que o intérprete quer que ele seja. Portanto, o direito não é aquilo que o intérprete, no seu conjunto ou na individualidade de seus componentes, dizem que é. Como mesmo afirma Lenio Streck, conjecturar essas proposições teóricas culminará na perda do "DNA do Direito", no sentido de que, ao deixar que se penetrem influências axiológicas do intérprete, da Economia e da Política de modo substitutivo da estrutura que lhe compõe, o Direito e sua identidade jurídico-institucional serão devastados.

A responsabilidade hermenêutica de cunho fenomenológico se apresenta incutida na superação desses equívocos epistemológicos, desvelando que a ideia de razão pragmáticodiscursiva se dilui com a morte daquele que a sustenta: o sujeito solipsista ${ }^{62}$. Para agregar ao debate, cabe mencionar a proposta de Dworkin, que ao contrário das teorias de Kelsen e Hart, não reside apenas na concepção de uma interpretação pela interpretação. Seu diferencial constitui em agregar à interpretação como modo construtivo ${ }^{63}$; trata-se, dessa forma, a construção e reconstrução de conceitos onde a interpretação melhor se enreda com a finalidade do Direito. Esta interpretação construtiva enfoca essencialmente na figura do intérprete, alertando, sobretudo, que por mais que as palavras sejam alográficas (e plurívocas), o intérprete não está autorizado a fazer disso uma prática livre e desprendida de qualquer responsabilidade $^{64}$. O Direito desvela-se assim na decisão, envolto em um todo principiológico comunitário forjado em "ideais" de integridade e coerência como condição primeira no construto decisório-hermenêutico-integrativo ao processo decisório democráticoconstitucional.

A hermenêutica de cariz filosófico sinaliza que aí se debruça a crença (metafísica e antidemocrática) que a "lei" possui uma "vontade", a qual será "revelada" na sentença,

\footnotetext{
61 "Não me importo o que pensam os doutrinadores. Enquanto for Ministro do Superior Tribunal de Justiça, assumo a autoridade da minha jurisdição (...) Decido, porém, conforme minha consciência. Precisamos estabelecer nossa autonomia intelectual, para que este Tribunal seja respeitado. É preciso consolidar o entendimento de que os Srs. Ministros Francisco Peçanha Martins e Humberto Gomes de Barros decidem assim, porque pensam assim. E o STJ decide assim, porque a maioria de seus integrantes pensa como esses Ministros. Esse é o pensamento do Superior Tribunal de Justiça, e a doutrina que se amolde a ele. É fundamental expressarmos o que somos. Ninguém nos dá lições. Não somos aprendizes de ninguém.” (BRASIL Superior Tribunal de Justiça, ERESP nº 279.889-AL).

${ }^{62}$ SALDANHA, Jânia Maria Lopes. Olhares Hermenêuticos sobre o Direito, op. cit., p. 85

${ }^{63}$ Dworking faz uma alusão à obra de arte, onde para esta, a interpretação de algo tem que descrever, ou melhor, mostrar qual a interpretação que desvela o "melhor de algo". Ou seja, qual a maneira de interpretar que revela a obra de arte, o que pressupõe construir e reconstruir conceitos. A isto chama-se de "hipótese estética". DWORKIN, Ronald. O Império do Direito. Tradução: Jefferson Luiz Camargo. São Paulo: Martins Fontes, 2007, p.202.

${ }^{64}$ Ibidem, p. 254.
} 
funcionando o processo judicial como um "caminho", uma "etapa”, para a obtenção dessa "clarificação". ${ }^{65}$ Baptista acusa que a jurisdição democrática não comporta esse modelo paradigmático; e que a "suposição de que a lei tenha uma 'vontade' suprime a Hermenêutica, no pressuposto de que a missão do julgador seja apenas a descoberta dessa 'vontade', para proclamá-la na sentença, como se a norma tivesse sempre o 'sentido' que lhe atribuíra o legislador", e isso "mesmo que as circunstâncias históricas e os padrões de moralidade sejam outros, inteiramente diversos daqueles existentes ao tempo da edição da lei". ${ }^{66}$

Declara Gadamer, que a compreensão da tradição e sua historicidade se edifica como a revolução mais importante da Idade Moderna, identificando-se pela plena consciência "de la historicidade de todo presente y de la relatividade de todas las opiniones". ${ }^{67}$ Nesse tear, repreende a dogmática jurídica afinada com o cientificismo, porque a humanidade não se encontra na "era da certeza", e sim da "incerteza jurídica". ${ }^{68}$

Ao adentrar nesta nova forma de sociedade transnacionalizada, qualquer perspectiva racionalista ligada ao normativismo-positivista se torna extremamente limitada. Nesse seguimento, em Dworkin a atividade do Direito é interpretativa. Afinando-se com a teoria gadameriana, edifica-se a interpretação enquanto caráter universal (interpretamos sempre, não apenas textos ou práticas sociais). Para mais, o caráter circular da hermenêutica, fazendo com que o intérprete seja parte daquilo que interpreta. ${ }^{69}$ Com esse discernimento, Cristiano Becker Isaia reforça uma busca "da" resposta constitucionalmente correta frente uma situação fática (que é sempre nova), onde através de uma filosofia no processo, tendo a linguagem como ponto de partida e de reflexão, o direito material-constitucional se desvelará. ${ }^{70}$

Para esse novo raiar hermenêutico-interpretativo, deixando no passado uma jurisdição metodológico-procedimental e, erigindo um novo modelo democrático-constitucional, no qual a interpretação construtiva, consoante aclara Francisco Motta, consiste na compreensão de algo (como um texto) onde deve ser considerado sua historicidade, mas que uma vez "dirigida por um interessse" (como atribuição de um sentido jurídico ao texto) do intérprete (este

\footnotetext{
${ }^{65}$ MOTTA, Francisco José Borges. Levando o direito a sério: uma crítica hermenêutica ao protagonismo judicial. op. cit. p.74.

66 BAPTISTA DA SILVA, Ovídio. Verdade e Significado. In: ROCHA, Leonel Severo; STRECK, Lenio Luiz. Constituição, Sistemas Sociais e Hermenêutica. Porto Alegre: Livraria do Advogado, 2005, p.268.

${ }^{67}$ GADAMER, Hans-Georg. El problema de la consciencia histórica. 2. ed. Traducido por Augustin Domingo Mortalla. Madrid: Editorial Tecnos, 2001, p. 41.

${ }^{68}$ ROCHA, Leonel Severo. Direito, Cultura Política e Sociedade. op. cit. p. 98.

${ }^{69}$ GADAMER, Hans-Georg. Verdade e método. Op. cit., p. 262.

${ }^{70}$ ISAIA, Cristiano Becker. Processo Civil e Hermenêutica: a crise do procedimento ordinário e o redesenhar da jurisdição processual civil pela sentença (democrática) liminar de mérito. Curitiba: Juruá, 2012, p. 193-195.
} 
também situado historicamente em seu tempo), edificará na "construção de um sentido novo", mas ainda assim "fiel ao texto". 71

Destarte, a viragem ontológico-linguística edifica-se como o raiar da nova possibilidade de constituição de sentido. Trata-se da "superação do elemento apofântico", com a introdução desse elemento prático que são as estruturas prévias que condicionam e precedem o conhecimento $^{72}$. Assim, é que o sentido não estará mais na consciência (de si pensamento pensante), mas, na linguagem, como algo que produzimos e que é condição de nossa possibilidade de estarmos no mundo. ${ }^{73}$

O caminho para se pensar um novo paradigma de jurisdição constitucional no interior de uma filosofia no Direito, guarda relação, pelo que se viu, com base em um constructo de abertura hermenêutica heideggeriana/gadameriana no afã de construir uma resposta constitucionalmente adequada.

\section{CONCLUSÃO}

A exposição da temática proposta procurou aduzir os dilemas que assolam o contexto jurídico-institucional atual, essencialmente pela marca cada vez mais progressiva da atividade jurisdicional, onde o protagonismo judicial acomete o Direito. Fazendo cada vez mais necessário o desafio de se repensar os pressupostos teóricos a fim de não permitir o esvaziamento do conteúdo democrático do atual Estado de Direito.

À vista disto, faz-se mister a importância de (re)discutir o problema metodológico discursivo-argumentativo entranhado no organismo jurídico-institucional, resultante de uma dogmática judicante alicerçada sobre a égide do esquema sujeito-objeto. A comunicabilidade de tais elementos acaba edificando-se como catalizador da "baixa efetividade" da Constituição Federal brasileira. Justamente o que causa o deslocamento da tensão decisória (como outros temas controversos) do Poder Legislativo e Executivo para o Poder Judiciário a fim de "satisfazer" às necessidades sociais, fenômeno norteado pelo paradigma da judicialização, onde o Judiciário se apresenta como instrumento-solução para consumação de direitos não realizados.

Por fim, não foi objetivo deste trabalho encerrar o tema, ou mesmo um ponto isolado dentro da Hermenêutica. Pelo contrário, ateve-se a entender/demonstrar que o processo

\footnotetext{
${ }^{71}$ MOTTA, Francisco José Borges. Levando o direito a sério: uma crítica hermenêutica ao protagonismo judicial. 2. ed. rev. e ampl. Porto Alegre: Livraria do Advogado, 2012, p.212-115.

${ }^{72}$ STEIN, Ernildo. Racionalidade e Existência: O ambiente Hermenêutico e As Ciências Humanas. op. cit., p.54.
} 
epistemológico-hermenêutico conduz a razão contra si, num retorno infinito ao questionamento. Só essa vigilância, constante e perene, desvela-se como capaz de solucionar (algumas d)as agruras exploradas neste artigo.

\section{REFERÊNCIAS}

ALEXY, Robert. Constitucionalismo discursivo. Tradução de Luís Afonso Heck. 2.ed. Porto Alegre: Livraria do Advogado, 2008.

BAUMAN, Zygmunt. Tempos líquidos. Tradução de Carlos Alberto Medeiros. Rio de Janeiro: Jorge Zahar, 2007, p.7

BERCOVICI, Gilberto. Ainda faz sentido a constituição dirigente? Revista do Instituto de Hermenêutica Jurídica: 20 anos de constitucionalismo democrático - e agora? Porto Alegre, vol. 1, n. 6, p.149-162. 2008.

BRASIL. Constituição da República Federativa do Brasil. Vade Mecum $12^{\circ}$ ed. São Paulo: Saraiva 2014.

CANOTILHO, José Joaquim Gomes. Constituição dirigente vinculação do legislador. Contributo para a compreensão das normas constitucionais programáticas. $2^{\mathrm{a}}$ ed. Coimbra: Coimbra Editora, 2001. e 2000 .

Direito Constitucional e Teoria da Constituição. $3^{\text {a }}$ ed. Coimbra: Almedina, 2006;

CAPPELlETTI, Mauro; GARTH, Bryant. Acesso à Justiça. Tradução de Ellen Gracie Northfleet. Porto Alegre. Sérgio Antônio Fabris, 2002.

CATTONI DE OLIVEIRA, Marcelo Andrade. Direito, política e filosofia: contribuições para uma teoria discursivo da constituição democrática no marco do patriotismo constitucional. Rio de Janeiro: Lumens Juris, 2007.

FARIAS, José Eduardo. As novas formas e funções do direito: nove tendências. In: Sociologia Jurídica: direitos e conjuntura. 2. Ed. São Paulo: Saraiva, 2010.

FERRAJOLI, Luigi. Derechos y garantias: La ley del más débil. Traducción de Perfecto Andrés Ibáñez y Andrea Greppi, 3a. ed. Madrid, Trotta, 1999.

- Sobre los derechos fundamentales. Tradução de Miguel Carbonell. In: CARBONELL, Miguel (Org.). Teoría del neoconstitucionalismo: ensayos escogidos. Madrid: Trotta, 2007.

GALEANO, Eduardo. Veias Abertas da América Latina. Tradução de Sergio Faraco. Porto Alegre: L\&PM, 2010.

${ }^{73}$ STRECK, Lenio Luiz. O que é isto - decido conforme minha consciência? op. cit., p. 68. 
GARCÍA-PELAYO, Manuel. As transformações do estado contemporâneo. Tradução de Agassiz Almeida Filho. Rio de Janeiro: Forense, 2009.

HEIDEGGER, Martin. Ser e Tempo. 3 ed. Tradução de Márcia de Sá Cavalcante Schuback. Petrópolis: Vozes, 2008.

HESSE, Konrad. A Força Normativa da Constituição. Porto Alegre: Sérgio Antônio Fabris, 1991.

HOBSBAWN, Eric. Tempos interessantes: uma vida no século XX. São Paulo: Companhia das Letras, 2002.

KUHN, Thomas. A estrutura das revoluções científicas. $6^{\text {a }}$ ed. São Paulo: Perspectiva, 2001.

KELSEN, Hans. Teoria pura do direito. Tradução de João Baptista Machado. São Paulo: Martins Fontes, 1999.

LÓPES MEDINA, Diego Eduardo. Teoría impura del derecho: La transformación de la cultura jurídica latino-americana. Bogotá: Legis, 2004.

LUCAS, Douglas César. Hermenêutica Filosófica e os limites do acontecer do direito numa cultura jurídica aprisionada pelo "procedimentalismo metodológico". In: LUCAS, Douglas César (Org.) Olhares hermenêuticos sobre o direito. Ijuí: Unijuí, 2007.

LYOTARD, Jean-François. O Inumano: considerações sobre o tempo. Tradução de Ana Cristina Seabra e Elisabete Alexandre. Lisboa: Estampa, 1990.

MOTTA, Francisco José Borges. Levando o direito a sério: uma crítica hermenêutica ao protagonismo judicial. 2. ed. rev. e ampl. Porto Alegre: Livraria do Advogado, 2012.

NUNES, Dierle José Coelho. Processo jurisdicional democrático. Curitiba: Juruá, 2011.

BAPTISTA DA SILVA, Ovídio. Verdade e Significado. In: ROCHA, Leonel Severo; STRECK, Lenio Luiz. Constituição, Sistemas Sociais e Hermenêutica. Porto Alegre: Livraria do Advogado, 2005.

ROCHA, Leonel Severo. Da epistemologia jurídica normativista ao construtivismo sistêmico. In: SCHWARTZ, Germano; CLAM, Jean. Introdução à teoria do sistema autopoiético do direito. Porto Alegre: Livraria do Advogado, 2005.

SALDANHA, Jânia Maria Lopes. Constituir a Constituição para a cidadania: A Compreensão e a Linguagem na Nova Crítica do Direito Afastando os Mitlaufers Jurídicos. In: Olhares Hermenêuticos sobre o Direito: em busca de sentido para os caminhos do jurista. Org. Douglas Cesar Lucas - Ijuí: Unijuí, 2007.

STEIN, Ernildo. Racionalidade e Existência: O ambiente Hermenêutico e As Ciências Humanas. 2a ed. Unijuí, 2008.

STRECK, Lenio Luiz. Aplicar a letra da lei é uma atitude positivista? Revista Novos Estudos 
Jurídicos - Eletrônica, vol. 15, n.1, p.158-173. Disponível em http://www.univali.br/seer/index.php/nej/article/view/2308. Acesso em: 20 abr.2015.

. Hermenêutica Jurídica e(m) crise. $8^{\text {a }}$ ed. Livraria do Advogado, 2009.

O que é isto - decido conforme minha consciência? Porto Alegre: Livraria do Advogado, 2010.

. Verdade e consenso: constituição, hermenêutica e teorias discursivas. $4^{\mathrm{a}}$. Ed. São Paulo: Saraiva, 2011.

STRECK, Lenio Luiz; BOLZAN DE MORAIS, Jose Luis. Ciência política e teoria do estado. 7. ed. Porto Alegre: Livraria do Advogado, 2010.

TASSINARI, Clarissa; BRAVO, Efendy E. M.; DEMRMMAM, Marina R.; KOCHE, Rafael; PINTO, Rafael S; sob orientação de Lenio Luiz Streck, Jose Luis Bolzan de Morais. Estudos sobre (neo)constitucionalismo. São Leopoldo: Oikos, 2009.

TASSINARI, Clarissa. Jurisdição e Ativismo Judicial: Limites da atuação do Judiciário. Porto Alegre: Livraria do Advogado Editora, 2013.

VIANNA, Luiz Werneck; CARVALHO, Maria Alice R de; MELO, Manuel P. Cunha; BARGOS, Marcelo B. A judicialização da política e das relações sociais no Brasil. Rio de Janeiro: Revan, 1999. 